\title{
LE PASSÉ SIMPLE, LE PARFAIT SIMPLE ET L'AORISTE : FRANÇAIS, ROUMAIN, VALAQUE ET SERBE \\ Marijana Petrović
}

Armand Colin | « Langages »

$2012 / 4 n^{\circ} 188$ | pages 59 à 74

ISSN 0458-726X

ISBN 9782200927776

Article disponible en ligne à l'adresse :

http://www.cairn.info/revue-langages-2012-4-page-59.htm

\section{Pour citer cet article :}

Marijana Petrović, « Le passé simple, le parfait simple et l'aoriste : français, roumain, valaque et serbe », Langages 2012/4 ( $\left.n^{\circ} 188\right)$, p. 59-74.

DOI 10.3917/lang.188.0059

Distribution électronique Cairn.info pour Armand Colin.

(C) Armand Colin. Tous droits réservés pour tous pays.

La reproduction ou représentation de cet article, notamment par photocopie, n'est autorisée que dans les limites des conditions générales d'utilisation du site ou, le cas échéant, des conditions générales de la licence souscrite par votre établissement. Toute autre reproduction ou représentation, en tout ou partie, sous quelque forme et de quelque manière que ce soit, est interdite sauf accord préalable et écrit de l'éditeur, en dehors des cas prévus par la législation en vigueur en France. Il est précisé que son stockage dans une base de données est également interdit. 


\section{Le passé simple, le parfait simple et l'aoriste : français, roumain, valaque et serbe}

Dans cet article ${ }^{1}$, notre attention portera sur l'expression de la notion d'événement (Desclés \& Guentchéva 1997, 2003, 2011) telle qu'elle se manifeste dans le domaine temporel du passé en français, roumain, valaque et serbe. Elle est signifiée le plus souvent par le passé simple en français, parfait simple en roumain et en valaque, et aoriste en serbe : des formes étiquetées différemment dans ces langues diverses se rapportent à un domaine sémantique relativement circonscrit, ce qui justifie notre rapprochement. Le passé composé, le parfait composé pour le roumain et le valaque, le parfait pour le serbe peuvent aussi exprimer la valeur aspectuelle de l'événement. Mais en réalité, ils possèdent deux valeurs fondamentales, événement et état résultant (d'un événement contigu et antérieur). L'événement, à travers son expression par des passés simples dans ces langues, est pris comme levier d'analyse pour montrer les convergences et les divergences linguistiques. La place et le rôle sémantique de ces formes se recoupent dans les sous-systèmes respectifs, et pourtant, malgré cette unité, la variabilité interlinguistique transparaît grâce à certains indices qui apparaissent dans le processus énonciatif. Nous prenons donc ici comme angle d'attaque les "référentiels énonciatifs »- notions développées dans le cadre théorique de J.-P. Desclés et Z. Guentchéva - pour traiter du passé simple. Cette articulation entre l'événement et les référentiels permet en réalité de réviser des classifications de langues faites d'un point de vue génétique, typologique et aréal. La démarche adoptée est à la fois onomasiologique et sémasiologique.

1. Je voudrais remercier Dejan Stosic, Zlatka Guentchéva, Jean-Pierre Desclés, Eleni Valma et Gergina Angelova pour leurs suggestions, ainsi que les relecteurs anonymes. Nonobstant, je reste seule responsable des erreurs éventuelles. 
Nous expliciterons d'abord les positions théoriques qui ont guidé nos choix, puis nous présenterons le passé simple/parfait simple/aoriste en français, roumain et serbe. Finalement, nous verrons pourquoi le valaque peut apporter des éléments de réflexion pour cette étude.

\section{POSITIONNEMENTS THÉORIQUES}

\subsection{Les langues, des systèmes}

Les langues prises en compte dans cette étude peuvent être classées selon des critères qui touchent à des domaines divers, la typologie et les familles linguistiques (romane $v s$ slave), la dialectologie et l'aréalité (domaine balkanologique). Pourtant ces classifications ne peuvent prédire le fonctionnement du passé simple.

Parmi les langues romanes, nous avons pris le français, qui appartient à la branche occidentale, et le roumain qui est issu de la branche orientale. Cependant, le roumain est géographiquement coupé de la Romania, ce qui lui confère des caractéristiques particulières. De la famille slave, nous avons inclus dans cette étude le serbe. Or, le serbe et les autres langues slaves du sud (le slovène, le macédonien ou le bulgare par exemple) sont aussi géographiquement isolés de l'ensemble slave.

Une autre classification, aréale cette fois-ci, nous intéresse. Le cœur du Sprachbund balkanique (Assenova 1989) est composé de l'albanais, du bulgare, du grec, du macédonien et du roumain. Le serbe est périphérique vis-à-vis de cette aire linguistique. On montre dans cet article que le comportement des passés simples mis en rapport avec les référentiels ne correspond pas à cette classification. Le roumain littéraire fonctionne comme le français, tandis que certaines variétés daco-roumaines (l'olténien et le valaque) et le serbe se rapprochent du Sprachbund.

Effectivement, le valaque n'a pas le même statut ${ }^{2}$ que le français, le roumain et le serbe qui sont les langues officielles des pays respectifs. Le valaque forme un ensemble de parlers daco-roumains, de tradition orale, dialectaux et périphériques au sud du Danube. Il évolue au contact avec le serbe, qui se substitue lentement au valaque - détail a priori externe à la langue et qui pourtant influence son système, y compris pour le passé simple. La première description linguistique, monographique, est celle de M. Petrović (2008a).

Outre ces oppositions, le rapprochement proposé ici présente aussi un intérêt typologique. Quelles que soient les étiquettes apposées à ces formes du passé,

2. Le terme 'valaque' est aussi appliqué aux populations méglénoroumaines et aroumaines dans tous les Balkans ainsi qu'aux parlers daco-roumains de Bulgarie. Ce mot a aussi servi à dénoter les 'bergers' ou d'autres peuples, tels les Serbes dans certaines régions de Croatie (Garde 2004). Aujourd'hui, c'est une minorité ethnique reconnue officiellement en Serbie. 
leur comparaison est possible pour plusieurs raisons. D'abord, d'un point de vue morphologique, les constructions sont parallèles : elles sont synthétiques pour les passés simples ${ }^{3}$ et l'imparfait, et analytiques pour les passés composés et ce, dans toutes les langues analysées ici. Le plus-que parfait est, en revanche, analytique en français et en serbe, et synthétique en roumain et en valaque. En outre, ces parallélismes morphologiques sont corroborés par des correspondances sémantiques. Les passés simples sont distribués de façon similaire dans ces langues, et ils expriment la valeur aspectuelle d'événement (Desclés \& Guentchéva 1997, 2003, 2011). Ces oppositions intrasystémiques permettent d'élaborer une comparaison dans un domaine sémantique défini qui est celui de la temporalité et de l'aspectualité, et elles permettent aussi une analyse de leur variabilité interlinguistique. Concrètement, les formes du passé qui sont en jeu sont celles illustrées dans le Tableau 1. Ce sont donc des sous-systèmes entiers (ceux du passé), à l'intérieur même de différents systèmes de langues, qui présentent des similitudes de fonctionnement.

Tableau 1 : Formes du passé en français, serbe, roumain et valaque

\begin{tabular}{|l|l|l|l|l|}
\hline Français & Passé composé & Passé simple & Imparfait & Plus-que-parfait \\
\hline Serbe & Parfait & Aoriste & Imparfait & Plus-que-parfait \\
\hline Roumain & Parfait composé & Parfait simple & Imparfait & Plus-que-parfait \\
\hline Valaque & Parfait composé & Parfait simple & Imparfait & Plus-que-parfait \\
\hline
\end{tabular}

\subsection{Typologie, dialectologie et contacts de langues}

La typologie offre un point de vue macrolinguistique, dont la vision globale permet de vérifier des hypothèses dans de nouvelles descriptions : étudier le valaque permet de compléter cette perspective avec une granularité microlinguistique qui se focalise très étroitement sur des parlers. Ce cheminement a été notamment proposé par B. Kortmann :

En plus de servir de source additionnelle riche et de contribuer considérablement à la typologie aréale, les données dialectologiques sont amenées à fournir de l'aide pour établir une granularité plus fine des paramètres typologiques et à formuler des généralisations et des hiérarchies qui sont en même temps plus fines et plus robustes. (Kortmann, $2003:$ 2)

Nous mettons en contraste la typologie avec la dialectologie pour mieux montrer leurs imbrications et leurs enrichissements mutuels. De plus, puisque le valaque évolue en Serbie, il est aussi nécessaire de traiter la question du contact des langues : W. Bisang (2003) propose dans ce même ouvrage d'enrichir le programme théorique de $\mathrm{B}$. Kortmann (allier la typologie à la dialectologie) avec ce troisième domaine (le contact de langues).

3. Nous nous référons au passé simple en sachant que ces formes sont étiquetées en tant que parfait simple et aoriste dans les autres langues. 
La problématique de l'unicité et de la variabilité trouve une réponse à travers cette démarche intégrative qui allie plusieurs champs disciplinaires de la linguistique, dont certains ont été négligés parfois - la dialectologie ou la Balkanologie par exemple. L'ouvrage de B. Kortmann (ed.) (2003) semble être le premier à défendre cette vision où la typologie se conjugue avec la dialectologie :

C'est une invitation émise d'une part pour ceux qu'intéresse la variation structurelle $\grave{a}$ l'intérieur des langues et, d'autre part, pour ceux qu'intéresse la variation structurelle à travers les langues. L'intention de cette invitation est de rassembler pour la première fois deux traditions de recherche dans l'étude de la variation de la langue (et du changement) qui jusqu'à maintenant ont évolué indépendamment l'une de l'autre, de les enrichir et de leur donner de manière réciproque de nouvelles perspectives. (Kortmann, $2003: 2$; notre traduction)

\subsection{Cadre théorique}

Le but ici a été de trouver une conceptualisation pour l'analyse qui soit susceptible de s'appliquer aussi bien à un niveau interlinguistique qu'intralinguistique. Ce n'est qu'une fois que les notions théoriques sont définies que nous pouvons avancer dans une comparaison micro- et macrolinguistique.

Nous situons notre recherche dans le cadre théorique développé par J.-P. Desclés (1995), Z. Guentchéva (1990), J.-P. Desclés et Z. Guentchéva (1997, 2003, 2011), dont la pertinence a été démontrée à travers des recherches portant sur des langues diverses (français, bulgare, arabe, ou encore coréen, etc.). Plusieurs notions développées dans cette théorie nous intéresseront ici.

Toute situation est aspectualisée, d'où la nécessité de prendre en compte les oppositions suivantes : état/événement/processus d'une part, et inaccompli/accompli/achevé d'autre part. Contrairement à $\mathrm{H}$. Reichenbach, dont les représentations en forme de points pour les formes verbales sont inscrites dans une temporalité linéaire, les valeurs aspecto-temporelles dans la conceptualisation de J.-P. Desclés et $Z$. Guentchéva sont représentées à l'aide d'intervalles topologiques avec des bornes ouvertes ou fermées. Un état est « une relation statique où aucun changement n'est pris en compte » et il est réalisé sur un intervalle dont les deux bornes sont ouvertes. Un événement « exprime une transition entre un état antérieur et un état postérieur » et il a été réalisé durant un intervalle dont les deux bornes sont fermées. Un processus en cours « exprime un changement ou une évolution affectant l'un des arguments de la relation prédicative "; dans sa représentation, il se réalise sur un intervalle dont la borne gauche est fermée, tandis que la borne droite est ouverte (Desclés \& Guentchéva 2011), indiquant ainsi qu'il s'agit d'un inaccompli. Les notions d'inaccompli, d'accompli et d'achevé s'appliquent à toute la relation prédicative.

Le processus est dit accompli lorsque la transformation qu'il opère n'est pas complète, c'est-à-dire que le processus est interrompu avant 'd'atteindre son terme'. [...] Le processus est dit achevé lorsque la transformation opérée est complète et qu'il n'est pas possible de la poursuivre ; le processus a donc atteint tout naturellement son état final. (Guentchéva, 1990 : 35) 
Toute situation est aussi ancrée dans la temporalité linguistique qui se distingue $\mathrm{d}^{\prime}$ autres conceptions du temps du fait même qu'elle intègre l'acte d'énonciation conçu comme un processus inaccompli. Ainsi :

L'énonciation est donc un processus qui se déroule dans le temps au sein du référentiel énonciatif. Le processus d'énonciation est fondamentalement inaccompli, car il se réalise durant un intervalle ' $\mathrm{J}_{0}$ ' $\mathrm{d}$ 'instants, avec un nécessaire premier instant de l'énonciation - donc avec une borne fermée à gauche $\gamma\left(\mathrm{J}_{0}\right)$ de l'intervalle ' $\mathrm{J}_{0}{ }^{\prime}{ }^{-}$, et sans dernier instant - donc avec une borne ouverte à droite $\delta\left(\mathrm{J}_{0}\right)$. (Desclés \& Guentchéva, 2011 : 99)

De cette conceptualisation découlent plusieurs référentiels temporels, lesquels s'organisent à partir du processus énonciatif. Le référentiel énonciatif (REN) est distinct du référentiel externe (le temps physique), et c'est l'énonciateur qui le crée en énonçant : le repère ' $\mathrm{T}^{0}$ ' est fixe, et il introduit une relation asymétrique entre le déjà réalisé et le pas encore. En outre, d'autres référentiels existent, tels les référentiels non actualisés (RNA), les référentiels rapportés (noté REN2), ceux des cadres de pensée, des situations possibles ou des connaissances partagées. Seuls les référentiels énonciatifs et le référentiel non actualisé devraient nous intéresser dans cet article :

[...] mais il nous paraît important de distinguer les différentes zones temporelles passées repérées par rapport à l'énonciation et donc faisant partie du référentiel REN, des zones temporelles de situations verbalisées qui ne peuvent plus être insérées dans le « réalisé » de l'énonciateur, ni situées dans un « à-venir » (Desclés \& Guentchéva 2006). Ces situations font donc partie d'un autre référentiel que le co-énonciateur reconnaît immédiatement comme marqueurs linguistiques de changement de référentiel en rupture avec le référentiel énonciatif REN. Dans ce nouveau référentiel, qualifié de référentiel non actualisé et désigné par RNA, tous les instants différenciés les uns des autres sont en relation de rupture avec tous les instants de REN, donc en particulier avec ' $\mathrm{T}^{0}$ '. (Desclés \& Guentchéva, $\left.2011: 110\right)$

Le référentiel énonciatif permet de rendre compte des relations temporelles repérées par rapport à la situation d'énonciation tandis que le référentiel non actualisé permet de relater des situations qui ne sont pas repérables par rapport à leur énonciation. Cette distinction rappelle celle de É. Benveniste (1966) entre « discours » et « histoire ». Mais, chez E. Benveniste, le concept de référentiel est absent, bien que, semble-t-il implicite. De plus, l'opposition de É. Benveniste ne permet pas de rendre compte de certaines narrations qui peuvent relever de l'histoire et être étroitement liées à leur énonciation. Introduire les référentiels permet de traiter ces phénomènes, que l'on introduira alors dans le référentiel énonciatif de l'énonciateur.

Cette grille conceptuelle nous permettra d'analyser les formes du passé simple/parfait simple/aoriste, en français, roumain, serbe et valaque. 


\section{PASSÉ SIMPLE, PARFAIT SIMPLE, AORISTE : FRANÇAIS, ROUMAIN, SERBE}

Notre objectif est de comparer ces formes dans différentes langues sur un point précis, à savoir le rapport qu'elles entretiennent avec les référentiels temporels. Dans ce qui suit, les formes verbales seront présentées de façon synthétique : l'aoriste, le passé simple et le parfait simple ont la valeur aspectuelle d'événement ${ }^{4}$.

\subsection{Le passé simple en français}

Les études concernant les formes du passé et du passé simple en français sont nombreuses, viser ici une analyse exhaustive est impossible. Nous renvoyons ainsi le lecteur à la bibliographie pour une description plus précise de cette forme en français ${ }^{5}$. Nous nous concentrons sur le passé simple analysé sous l'angle de l'opposition REN/RNA.

En français ${ }^{6}$, le passé simple désigne toujours des événements qui s'inscrivent dans une structure de succession où un événement précède ou suit un autre événement ; ceux-ci ne s'inscrivent pas en général dans le référentiel énonciatif, mais plutôt dans le RNA ; le passé composé renvoie aussi à des événements et, selon les contextes, à des états résultants, mais qui sont aussi repérables dans le REN et dans le RNA ${ }^{7}$.

Les auteurs de la Grammaire méthodique du français concluent leur chapitre sur le sujet de la manière suivante (Riegel, Pellat \& Rioul, 1994 : 304) : "Le passé simple, coupé de la situation d'énonciation, rejette l'énoncé dans un passé révolu nettement délimité ; sa valeur générale est limitée temporellement ». Dans cette description grammaticale, on insiste sur une limitation temporelle de la forme ainsi que sur une coupure entre le moment de l'énonciation et l'événement rapporté. Si la question de la « limite temporelle » demeure empirique, la question de la coupure et $\mathrm{du}$ " passé révolu » nous invite à penser que le passé simple est rejeté de la situation de l'énonciation ; dans ce cas, il se trouve ailleurs.

Dans les analyses de J.-P. Desclés et Z. Guentchéva :

4. Pour une comparaison globale de toutes les formes du passé en valaque, roumain et serbe, nous renvoyons le lecteur à Petrović (sous presse).

5. Bres 1997 ; Eberle \& Kasper 1994 ; Kamp \& Rohrer 1983 ; Leeman 2003 ; Molendijk 1990 ; Nølke 2003 ; Touratier 1996 ; Vet 1980 ; Vetters 1993 ; pour ne citer que quelques références dans des cadres théoriques et des perspectives de recherche différents.

6. La présence du passé simple est liée aussi au registre de la langue, sa fréquence est plus importante dans le français formel qu'informel. Beaucoup de chercheurs (Weinrich 1973, par exemple) placent les situations au passé simple « au premier plan », dans le foreground, mais Waugh \& Monville-Burston (1986) montrent que ce ne serait pas le cas dans les journaux. En effet, certains énoncés avec des imparfaits ont cette fonction discursive de « premier plan », notamment avec les imparfaits de « nouvel état».

7. Par manque de place, nous renvoyons le lecteur à Desclés \& Guentchéva (2003) pour une étude complète concernant le passé composé. 
Le passé simple est une forme qui, dénotant toujours un événement, relève du référentiel non actualisé RNA et pratiquement jamais, en français contemporain, du référentiel énonciatif REN ; son emploi peu fréquent dans l'oral s'explique puisque l'oralité est étroitement liée à des dialogues relevant du référentiel énonciatif REN ou de référentiels de propos rapportés REN2. (Desclés \& Guentchéva, 2011 : 111)

Prenons un exemple tiré de cet article :

(1) Depuis une heure, il avançait ainsi, lorsque sur la gauche, à deux kilomètres de Montsou, il aperçut des feux rouges, trois brasiers brûlant au plein air, et comme suspendus. D'abord, il hésita, pris de crainte ; puis, il ne put résister au besoin douloureux de se chauffer un instant les mains. (Zola, Germinal)

L'occurrence de l'imparfait renvoie ici à la valeur aspectuelle de processus ('avançait'), qui permet de construire « un cadre temporel de référence narrative » ; les événements exprimés au passé simple ('aperçut', 'hésita', 'ne put résister') y entrent :

[ils] font irruption à l'intérieur de ce cadre en créant une structure narrative de succession : un événement succède à un autre événement dans le cadre déjà établi ; parfois un événement vient complètement modifier ce cadre. Aucun déictique ne vient donner une indication temporelle qui permettrait d'établir une relation quelconque avec le processus énonciatif qui pourtant prend en charge la narration. (Desclés \& Guentchéva, 2011 : 111)

Nous pourrions aussi reprendre quelques exemples de la Grammaire méthodique du français (Riegel, Pellat \& Rioul, 1994 : 304) qui s'avèrent prototypiques de cet usage dans les contes (2) ou pour exprimer des vérités générales (3) :

(2) Le Chat devint grand Seigneur, et ne courut plus après les souris, que pour se divertir. (Perrault)

(3) Qui ne sait se borner ne sut jamais écrire. (Boileau)

\subsection{Le parfait simple en roumain}

Comme pour le passé simple en français, le parfait simple en roumain dénote l'événement repéré dans le RNA. Malheureusement, peu d'études linguistiques s'avèrent réellement consacrées à l'analyse des valeurs sémantiques de cette forme en roumain, raison pour laquelle nous faisons appel aux grammaires. Dans V. Guţu-Romalo (ed.) (2008 : 422), les valeurs du parfait simple sont présentées comme similaires à celles du parfait composé, à savoir, antériorité au moment de l'énonciation, valeur aspectuelle « perfective » et modalité + Realis. Le terme " perfectif » est très contestable, car il est étroitement lié à une distinction morphologique qui est identifiable dans les langues slaves (voir par exemple Guentchéva 1990 ; Thomas 1998a) et ne permet pas une conceptualisation aspectuelle qui ouvrirait le champ à une comparaison générale entre différentes langues. M. Haase (1994 : 140), ainsi que V. Guţu-Romalo (ed.) (op. cit. : 423) et E. ArjocaIeremia (à par.), précisent que le parfait simple est une forme littéraire ou alors utilisée régionalement, en Olténie. Une nouvelle fois, les définitions insistent sur la fonction essentielle du parfait simple dans la narration. Les valeurs qu'ils 
attribuent au parfait simple et parfait composé sont les mêmes, sans que leurs différences fonctionnelles soient explicitées dans V. Guţu-Romalo (ed.) (2008) ou chez M. Haase (1994 : 140). Ce dernier introduit néanmoins une opposition entre les deux, puisque le PC est reclassé en tant que present anterior. D'après notre analyse, les deux formes dénotent l'événement mais, alors que le parfait simple s'inscrit dans le RNA, le parfait composé place la situation dans le REN ou le RNA. Ce dernier peut, par conséquent, alterner avec le PS :

(4) Nemţii se răspândiră (PS) în sat şi luară (PS) mai mulţi ostateci.

Les Allemands se dispersèrent dans le village et prirent plusieurs otages. (Arjoca-Ieremia)

(5) Nemţii s-au răspândit (PC) în sat şi au luat (PC) mai mulţi ostateci. Les Allemands se dispersèrent dans le village et prirent plusieurs otages.

En revanche, un déictique temporel tel que hier ('ieri'), qui déplacerait donc de fait cette phrase dans le REN, se combine plus aisément avec cet exemple au PC comme dans (6), tandis que le résultat serait plus maladroit avec le PS :

(6) Ieri, Nemţii s-au răspândit (PC) în sat şi au luat (PC) mai mulţi ostateci.

Hier, les Allemands se dispersèrent dans le village et prirent plusieurs otages.

Même si le PS est confiné à la narration dans le domaine littéraire avec une fréquence en baisse (Avram, $1997: 226$; Avram, 1984 : 544), il dénote toujours la notion d'événement et situe normalement cet événement dans le RNA. Le PC exprimerait, en revanche, l'événement lorsqu'il est inscrit dans le REN, ainsi que l'état résultant dans le REN et le RNA. Cependant, il existe un emploi qualifié $\mathrm{d}^{\prime}$ " ironique » dans les différents travaux (Arjoca-Ieremia à par. ; Avram, 1997 : 226 ; Guţu-Romalo (ed.), $2008: 422$; Haase, $1994: 141$ ) qui nous invite à réfléchir à la possibilité d'introduire, de façon très marginale, le parfait simple dans le REN pour l'oral et dans un registre informel. Cet emploi ironique est à mettre en rapport avec l'usage du PS dans les parlers olténiens (Arjoca-Ieremia à par. ; Brîncuş, 1957 : 161 ; Guţu-Romalo (ed.), 2008 : 423 ; PanăBoroianu, 1982 : 434), où le PS est employé à la place du PC dans le REN :

(7) - Unde fuseşi (PS) ?

- Fusei (PS) la pită, lapte ; luai (PS) şi nişte ouă.

- Où as-tu été ? (PS)

- Je suis allée acheter du pain, du lait. J'ai pris (PS) aussi des œufs. (ArjocaIeremia)

Malheureusement, les auteurs se restreignent habituellement à une explication diatopique ( régionalisme ») et diaphasique ( narration littéraire » et ironie pour l'oral), dans les termes de F. Gadet (2003 : 15), sans analyser les valeurs du PS, en particulier lorsqu'elles l'évoquent en tant que " passé immédiat » (Graur (ed.), 1966 : 238). A. Graur (ed.) (1966) se fonde sur la description de G. Brîncuş (1957 : 161), qui parle en réalité de " passé du jour » : cet article est fondateur pour l'analyse de cette forme en roumain dialectal, seulement, il est daté et presque toujours cité à mauvais escient. 


\subsection{L'aoriste en serbe}

Contrairement aux langues romanes, le serbe possède un système verbal complexe du point de vue de la morphologie temporelle et aspectuelle. Il a gardé notamment quatre formes pour l'expression du passé et présente une opposition morphologique entre des verbes perfectifs et imperfectifs - opposition que l'on retrouve au passé, présent et futur (cf. Thomas 1993, 1998b). Comme le soulignent P.-L. Thomas (2005 : 199), et P. Piper et al. (2005 : 427), l'aoriste est de préférence utilisé avec des verbes perfectifs.

De même qu'en français et en roumain, l'aoriste en serbe renvoie à la valeur aspectuelle d'événement. Mais l'aoriste en serbe peut décrire les situations relevant aussi bien du RNA (8) que du REN (9) :

(8) Rakija koju momci donesoše (PS) i cicvara koja zacvrča (PS) na vatri pored njih prekinuše ovaj dijalog.

L'eau de vie que les jeunes hommes apportèrent (PS) et la bouillie qui se mit à grésiller (PS) sur le feu à côté d'eux arrêtèrent ce dialogue. (Travnička Hronika, Ivo Andrić)

(9) Sonja, tvoju crnu kosu bezbroj puta u snu mrsih (AO) ja.

Sonja, tes cheveux noirs, je les ai emmêlés $(\mathrm{AO})$ en rêve à l'infini. (Sonja, Ljiljana Butler-Petrović)

Si on modifie l'énoncé (8) en lui ajoutant un déictique temporel tel que à l'instant ('upravo sada'), nous déplaçons explicitement cet exemple dans un REN, sans que ce test ne modifie la grammaticalité de la phrase :

(10) Rakija koju momci donesoše (PS) i cicvara koja zacvrča (PS) na vatri pored njih prekinuše ovaj dijalog, upravo sada.

L'eau de vie que les jeunes hommes apportèrent (PS) et la bouillie qui se mit à grésiller (PS) sur le feu à côté d'eux arrêtèrent ce dialogue, à l'instant.

Dans P. Piper et al. (2005: 424), l'aoriste est présenté comme ayant deux fonctions essentielles : " l'expression d'actions qui ont eu lieu dans le passé immédiat du moment d'énonciation, et des actions qui se sont passées bien avant le moment d'énonciation ». De plus, "l'aoriste exprime toujours une action passée vécue ou présentée comme telle » et il est apte à rendre la succession des événements (op. cit. : 425). Cependant, la grammaire précise que la notion de passé immédiat est relative et qu'elle doit être évaluée en fonction du contexte plus large, comme dans l'exemple (10) que l'on peut opposer à (11). Au final, expliquer l'aoriste ainsi ne le définit pas, d'autant plus que la question de la distance temporelle est intuitive et contextuelle. T. Ašić et V. Stanojević (2007) parlent plutôt « d'un événement qui est d'actualité, pertinent au moment d'énonciation ».

(11) Deca odoše u grad, a mi stariji još živimo na selu.

Les enfants sont partis $(\mathrm{AO})$ à la ville, mais nous, les plus âgés, nous sommes restés vivre (PR) à la campagne. (Piper et al., 2005 : 424)

Zaboravih naočare.

J'ai oublié mes lunettes (AO).

Ces exemples sont aussi compatibles avec un parfait (13) et (14) : 
(13) Deca su otišla (P) u grad, a mi stariji još živimo na selu.

Les enfants sont partis $(\mathrm{P})$ à la ville, mais nous, les plus âgés, nous sommes restés vivre $(\mathrm{PR})$ à la campagne.

Zaboravila sam naočare.

J'ai oublié mes lunettes $(\mathrm{P})$.

Mais l'aoriste en serbe peut aussi dénoter un événement qui se déploie dans une narration inscrite dans le REN (15) :

(15) Odoh (AO) ja onda do policije...

Je suis allé(e) (AO) alors à la police...

Notre analyse n'est pas en désaccord avec les visions présentées ici («passé immédiat » ou « vécu », " pertinence au moment de l'énonciation »), mais dans l'analyse que nous faisons de l'aoriste, il serait un événement inscrit dans le REN. P.-L. Thomas (1998a : 23) signale que ces emplois de "passé immédiat » sont les plus fréquents à la première personne du singulier ; il rappelle qu'il existe aussi « une transposition métaphorique de la valeur de passé immédiat : 1'action est présentée comme venant d'être accomplie, alors qu'elle ne l'est pas encore et qu'elle a même de fortes chances de ne pas se réaliser » surtout au vu de l'exemple suivant que nous reprenons à P.-L. Thomas (ibid.) :

Crkoh od gladi!

Je crève (je suis mort, j’ai crevé) de faim !

P.-L. Thomas (1998a, 2005 : 199) a porté une attention particulière à l'emploi de l'aoriste dans le récit, que nous interprétons une nouvelle fois d'emploi de l'aoriste dans le RNA. En témoigne l'exemple suivant tiré de l'article de P.-L. Thomas (2005 : 195) :

(17) Vojnici ga odvedoše u nutrinu palače, u takozvani pretorij, te sazvaše cijelu četu. Ogrnuše ga skrletnom kabanicom, pa opletoše trnovu krunu i njom ga okruniše. Tada ga počeše pozdravljati : "Zdravo, kralju židovski !"

Les soldats l'emmenèrent à l'intérieur du palais, qui est le Prétoire, et ils convoquent toute la cohorte. Ils le revêtent de pourpre, puis, ayant tressé une couronne d'épines, ils la lui mettent. Et ils se mirent à le saluer : «Salut, roi des Juifs ! ». (Traduction de la Bible de Rupčić, et de la Bible de Jérusalem pour le français)

Ainsi, si l'aoriste en serbe renvoie à des événements comme en français et en roumain, il se distingue de ces langues par son aptitude à les situer dans deux référentiels, le référentiel énonciatif et le référentiel non actualisé. 
Le passé simple, le parfait simple et l'aoriste : français, roumain, valaque et serbe

\section{LE VALAQUE}

\subsection{Description}

Même si les formes verbales sont étiquetées de façon identique en roumain et en valaque $^{8}$, le fonctionnement des formes du passé diffère dans ces deux variétés alors que leurs valeurs sémantiques peuvent se recouper (Petrović sous presse). L'événement est la valeur aspectuelle rattachée au parfait simple en valaque, comme l'illustre l'exemple (18), ici, dans une narration inscrite dans le REN :

(18) Muri (PS) šî mumă-sa.

Sa mère aussi est morte (PS).

Cet énoncé peut aussi être mis au PC (19), en gardant une narration dans le REN :

A murit (PC) šî mumă-sa.

Sa mère aussi est morte $(\mathrm{PC})$.

Le parfait simple s'inscrit dans le RNA (20) et (21) aussi bien que dans le REN, comme le montre l'exemple (22) qui est une interlocution complète entre trois énonciateurs où le parfait simple est quasiment la seule forme verbale, avec un seul présent, $n u$ šću 'je ne sais pas' :

(20) Da kînd să kulkă vulpija pe drum ?

Et quand le renard se coucha (PS) sur la route?

(21) Fata ješî, šî jej o mînkară ! Numa đinci uđiră !

La fille sortit (PS), et ils la mangèrent (PS) ! Seules les dents restèrent (PS) !

(22) Vera : Šazuj će ai's ku jej.

'Je me suis assise (PS) avec eux.'

Zora : Da numa juo flamîndă ?

'Et je suis la seule à avoir faim ?'

Vlasta : Mînkarăm ! Kă pănă akuma mînkarăm !

'On a mangé (PS) ! On a mangé (PS) jusqu'à maintenant !'

Vera : Velja să skulă šî flamînd, da šî nuoj kă vremja prînzuluj. Ama nu šću, da l' să dusă jel vrunđiva...

'Velja s'est levé (PS), et il avait faim, et nous aussi, car c'était l'heure du déjeuner. Mais je ne sais pas (PR), il est parti (PS) quelque part...'

Zora : Să dusă jel la Buljuoc. Vazuj karu akolo, da juo nu kă...

'Il est parti (PS) à Boljevac. J'ai vu (PS) la voiture là-bas, parce que moi je n'[ai] pas...'

Les anecdotes foisonnent de parfaits simples. Étant donné qu'ils présentent des événements (Guentchéva, $1990: 35^{9}$ ), les verbes au parfait simple peuvent introduire facilement des situations nouvelles dans les narrations, ou rentrer dans une chaîne d'événements successifs. Le PS peut alterner avec le parfait

8. Tous les exemples sont tirés d'enquêtes de terrain de première main effectuées en Serbie et financées par le LACITO.

9. Le terme d' " achèvement » ici ne doit pas être confondu avec "Achievement" de Vendler (1957) qui renvoie à du ponctuel. La classification de Vendler ne se confond pas avec les notions explicitées chez Guentchéva (1990). 
composé, qui partage avec le parfait simple la valeur aspectuelle d'événement (18-19). Il arrive aussi que des histoires entières soient présentées au PS ${ }^{10}$. Les exemples (23), (24) et (25) sont aussi des exemples attestés, tirés de différentes histoires vécues, et ces exemples sont des narrations qui s'inscrivent dans le REN.

(23) Venji o vi'zuljije, numa 'se skaparăm đe akolo. Une tempête est arrivée (PS), on avait juste eu le temps de nous enfuir (PS) de là-bas.

(24) Făkuj kolješă, măj ạm avut šî brînză vro duaă faljij, mînkarăm binje. J'ai fait (PS) une polenta, et j'avais (PC) encore quelque chose comme deux morceaux de fromage, nous avons bien mangé (PS).

(25) Fată uaja-ja, 'se să fak akuma ku mjelo-la ? Kotarica-ja, îl dusăj în kotarica. La brebis a mis bas (PS), qu' est-ce que j'allais faire (PR) maintenant avec cet agneau ? Le panier, je l'ai emporté (PS) dans le panier.

Mais le parfait simple en valaque est aussi extrêmement fréquent dans le REN en dehors de la narration, comme peuvent l'attester les énoncés (26) et (27). L'énoncé (26) est l'expression consacrée lorsqu'une idée échappe à un énonciateur, tandis que la phrase (27) est exprimée lorsque surgit un événement auquel l'énonciateur ne s'attendait pas - comme, par exemple dans ce cas, une tasse de café renversée sur les genoux de l'énonciatrice.

(26) Đeć 'seva să spun...

Je voulais (PS) dire quelque chose...

Aflaj pe Draku!

J'ai trouvé (PS) le Diable!

En conclusion, le PS en valaque renvoie à la valeur aspectuelle d'événement, et les situations auxquelles il se rattache relèvent aussi bien du REN que du RNA.

\subsection{L'unité et la variabilité dans les langues}

La synthèse pour ces langues est simple : le passé simple en français, le parfait simple en roumain et en valaque, l'aoriste en serbe renvoient à la valeur aspectuelle d'événement, mais le rôle que cette forme joue dans le cadre des référentiels implique, entre autres, une distribution différente selon les langues.

Le parfait simple en français et en roumain littéraire se situe dans le RNA. Tout porte à croire qu'en roumain dialectal d'Olténie, où le parfait simple serait selon les descriptions une forme conservatrice, il s'inscrirait dans le REN. L'aoriste en serbe rentre aussi bien dans les constructions REN que RNA, ainsi qu'en valaque. Selon ce critère, les deux langues romanes, à savoir le français et le roumain, fonctionneraient de la même manière. En revanche, le dialecte roumain d'Olténie, le serbe et le valaque, en plaçant le PS dans les deux référentiels, se rejoignent : deux variétés du daco-roumain se rapprochent de la langue slave.

10. On trouvera un tel exemple dans Petrović (sous presse). 


\subsection{Questions et hypothèses}

Est-ce un hasard si le valaque fonctionne de la même manière que le dialecte olténien voisin et le serbe ? Il serait sans doute erroné de le croire, cela pour deux raisons. Comme il a déjà été montré dans un travail antérieur (Petrović 2010), le valaque est à mettre en parallèle avec deux dialectes daco-roumains, le dialecte du Banat et de l'Olténie. Par conséquent, il n'est pas étonnant que le valaque partage le même trait pour le parfait simple que le dialecte olténien. D'autre part, le serbe possède la même propriété. S'agirait-il alors d'un phénomène de contact de langues, puisque le valaque évolue au contact avec le serbe ? C'est sans doute le cas.

Dans cette configuration, il serait pertinent de penser que ces deux influences ne s'opposent pas, mais se renforcent l'une l'autre. Le parfait simple serait un élément conservateur en valaque, comme en Olténie. Le fait que le serbe possède la même propriété renforcerait alors cet archaïsme : ce ne serait donc pas un emprunt à proprement parler, mais une consolidation d'un fait déjà existant en langue. De plus, K. Sandfeld ([1930] $1968: 105)$ signale un usage similaire en aroumain, ce qui renforcerait l'idée d'un balkanisme.

\section{CONCLUSION}

Nous obtenons alors une classification qui diverge de celle communément admise en Balkanologie et que nous pouvons résumer dans le tableau suivant, en y incluant le français qui endosse alors le rôle d'une langue romane témoin :

Tableau 2 : Classification des langues étudiées

\begin{tabular}{|l|l|l|}
\hline Langues & PS et REN & PS et RNA \\
\hline Français & Rare & Oui \\
\hline Roumain & Rare & Oui \\
\hline Valaque & Oui & Oui \\
\hline Serbe & Oui & Oui \\
\hline Bulgare & Oui & Oui \\
\hline Grec & Oui & Oui \\
\hline Albanais & Oui & Oui \\
\hline
\end{tabular}

D'une part, pour le français et le roumain standard, l'appartenance à la même famille linguistique romane semble primer sur l'appartenance du roumain au Sprachbund balkanique, qu'il ne rejoint pas complètement sur ce critère. Mais le roumain dialectal d'Olténie, qui par définition échappe à la standardisation, semble rejoindre l'union balkanique, au même titre que les autres langues standard des Balkans. La surprise proviendrait alors du serbe, qui, sans faire partie du Sprachbund, s'en rapproche par le fonctionnement de l'aoriste relativement au REN/RNA. Finalement, le valaque montre qu'il a un comportement très balkanique sur ce point, et qu'il se rapproche sur ce fait de l'aroumain. 
Étant donné que ces langues ou variétés de langues sont présentées en parallèle dans cet article pour la première fois, il ne nous est malheureusement pas possible pour des questions de limites éditoriales d'être exhaustive en ce qui concerne notamment tous les emplois du PS et d'approfondir toutes ces analyses en incluant, par exemple, une étude basée sur les types de procès selon $\mathrm{Z}$. Vendler, ou une comparaison systématique avec les PC - autant de prospectives.

Cette étude se limite à présenter la notion d'événement à travers les formes verbales que sont le passé simple, le parfait simple et l'aoriste, en français, en roumain littéraire et dans son dialecte olténien, en valaque et en serbe. Pour autant, si ce concept trouve son expression parallèlement dans toutes ces langues ou variétés, il s'avère qu'il existe un critère qui nous permet de distinguer leurs fonctionnements selon que l'événement s'inscrit dans le REN ou le RNA. À une seule et même valeur sémantique correspondent plusieurs formes linguistiques dans et à travers les langues : l'héritage linguistique, la typologie, le contact des langues et la balkanologie se croisent comme autant d'indices de l'unité linguistique comme de ses divergences. Preuve, s'il en faut, que les langues sont à analyser dans toute leur complexité : comment une langue évolue ou conserve des éléments, en situation de contact linguistique - le valaque, par exemple, emprunte le préfixe verbal do- du serbe (Petrović 2008b), ce qui a pour conséquence de bouleverser complètement un système aspectuel roman...

\section{Références}

ARJocA-leREMIA E. (à par.), "Convergences et divergences dans l'emploi du passé simple en français et en roumain ", Filološki Pregled, Beograd : Filološki Fakultet.

AsSENova P. (1989), Balkansko ezikoznanie, Sofia : Nauka i izkustvo.

Ašić T. \& STANOJEVIĆ V. (2007), "O upotrebi glagolskih vremena u razgovornom srpskom jeziku zasto aorist ipak opstaje ?”, Zbornik Skupa Srpski jezik, knjizevnost u umetnost, Kragujevac, 37-55.

AVRAm L. (1984), “A few remarks on tense and aspect in Romanian”, Revue Roumaine de Linguistique 24 (6), 537-545.

Avram M. (1997), Gramatica pentru toţi, Bucureşti : Humanitas.

BenveNISTE É. (1966), Problèmes de linguistique générale, Paris : Gallimard.

BISANG W. (2003), “Dialectology and Typology - An integrative perspective”, in B. Kortmann (ed.), Dialectology meets Typology, Dialect grammar from a crosslinguistic perspective, Berlin/New York: Mouton de Gruyter, 11-45.

BRES J. (1997), "Habiter le temps : le couple imparfait/passé simple en français ", Langages 127, 77-95.

BRîncuş G. (1957), " Sur la valeur du passé simple en roumain ", Mélanges linguistiques, publiés à l'occasion du VIII Congrès International des Linguistes à Oslo (du 5 au 9 août 1957), Bucarest : Académie de la République Populaire Roumaine, 159-174.

DESCLÉS J.-P. (1995), "Les référentiels temporels pour le temps linguistique ", Modèles linguistiques XVI (2), 9-36. 
Le passé simple, le parfait simple et l'aoriste : français, roumain, valaque et serbe

DESCLÉS J.-P. \& GUENTCHÉVA Z. (1997), " Aspects et modalités d'action (représentations topologiques dans une perspective cognitive) ", Studia Kognitywne : Semantyka kategorii aspektu i czasu, Varsovie : Académie des sciences de Pologne \& Instytut Slavistyki, 145-174.

Desclés J.-P. \& GuentChÉva Z. (2003), "Comment déterminer les significations du passé composé par une exploration contextuelle ? ", Langue française 138, 48-60.

DescLÉS J.-P. \& GUENTCHÉVA Z. (2006), " Référentiels aspecto-temporels dans les textes ", Studia Kognitywne 7, 11-38.

DESCLÉS J.-P. \& GUENTCHÉVA Z. (2011), "Référentiels aspecto-temporels : une approche formelle et cognitive appliquée au français ", Bulletin de la Société Linguistique de Paris CVI (1), 95-127.

EberLE K. \& KASPER W. (1994), "French Past Tenses and Temporal Structure”, in R. Thieroff \& J. Ballweg (eds), Tense systems in European Languages, Tübingen: Max Niemeyer Verlag, 149-172.

GADET F. (2003), La variation sociale en français, Paris/Gap : Ophrys.

GARDE P. (2004), Le discours balkanique, Des mots et des hommes, Paris : Fayard.

Graur A. (ed.) (1966), Gramatica Limbii Române, Bucarest: Editura Academiei Republicii Socialiste România.

GUENTCHÉVA Z. (1990), Temps et aspect : l'exemple du bulgare contemporain, Paris : Éditions du CNRS.

Guțu-Romalo V. (ed.) (2008), Gramatica Limbii Române, I, Cuvântul, Academia Română, Bucarest : Editura Academiei Române.

HAASE M. (1994), “Tense, Aspect and Mood in Romanian”, in R. Thieroff \& J. Ballweg (eds), Tense systems in European Languages, Tübingen: Max Niemeyer Verlag, 135-152.

KAMP H. \& Rohrer C. (1983), "Tense in texts", in R. Bauerle, C. Schwarze \& A. von Stechow (eds), Meaning, Use, and Interpretation of Language, Berlin/New York: de Gruyter, 250-269.

KortmAnn B. (ed.) (2003), Dialectology meets Typology, Dialect grammar from a crosslinguistic perspective, Berlin/New York: Mouton de Gruyter.

Kortmann B. (2003), “Introduction”, in B. Kortmann (ed.), Dialectology meets Typology, Dialect grammar from a crosslinguistic perspective, Berlin/New York: Mouton de Gruyter, 1-10.

LEEMAN D. (2003), "Le passé simple et son co-texte : examen de quelques distributions ", Langue française 138, 20-34.

MolENDIJK A. (1990), Le passé simple et l'imparfait : une approche reichenbachienne, Amsterdam : Rodopi.

NøLKE H. (2003), " Le passé simple subjectivisé ", Langue française 138, 75-85.

PanĂ-Borolanu R. (1982), "Remarques sur l'emploi du passé simple dans les textes non littéraires d'Olténie ", Revue Roumaine de Linguistique XVII (5), 423-434.

Petrović M. (2008a), Description syntaxique et sémantique du valaque (parler daco-roumain de Serbie), Thèse de l'Université Paris Sorbonne.

Petrović M. (2008b), "Do- : étude d'un préfixe verbal en valaque ", in B. Sikimić \& T. Ašić (eds), The Romance Balkans, Collection of papers presented at the international conference 'The Romance Balkans', 4-6 November 2006, Belgrade : Institut des études balkaniques, 261-288.

Petrović M. (2010), "Éléments dialectologiques de Valakonje ", in N. Saramandu, M. Nevaci \& C.-I. Radu (eds), Lucrările celui de al treilea Simpozion Internaţional de Lingvistică, Bucureşti, 20-21 noiembrie, 2009, Bucarest : Editura Universităţii din Bucureşti, 119-128. 
Petrović M. (sous presse), "Le passé en valaque ", in C. Chamoreau \& L. Goury (éds), Conséquences linguistiques du contact de langues et changements linguistiques. Tendances dans le domaine de la prédication, Paris : CNRS éditions.

PIPER P. et al. (eds) (2005), Sintaksa savremenoga srpskog jezika, Prosta rečenica, Institut za srpski jezik, SANU, Beograd : Beogradska Knjiga, Matica srpska.

Riegel M., Pellat J.-C. \& Rioul R. (1994), Grammaire méthodique du français, Paris : Presses Universitaires de France.

SANDFELD K. ([1930] 1968), Linguistique balkanique : problèmes et résultats, Paris : Klincksieck.

STANOJČı́ Ž. \& PoPović Lj. (2000), Gramatika srpskoga jezika, Udžbenik za I, II, III I IV razred srednje škole, Beograd : Zavod za udžbenike i nastavna sredstva.

Thomas P.-L. (1993), "Bilan des recherches sur l'aspect en serbo-croate ", Revue des Études Slaves 65, 537-550.

THomas P.-L. (1998a), " Aoriste, aoristique et systèmes d'énonciation : le cas du serbo-croate (bosniaque, croate, serbe) ", Le langage et l'homme 33 (1), 21-38.

Thomas P.-L. (1998b), "Remarques sur l'aspect en serbo-croate ", in A. Borillo, C. Vetters \& M. Vuillaume (éds), Regards sur l'aspect, Amsterdam : Rodopi, 231-246.

ThomAS P.-L. (2005), "Recomposition du système aspecto-temporel en serbo-croate (bosniaque, croate, monténégrin, serbe) ", in A. Molendijk \& C. Vet (éds), Cahiers Chronos $\mathrm{n}^{\circ} 12$ : Temporalité et attitude, Structuration du discours et expression de la modalité, Amsterdam/Atlanta : Rodopi, 187-201.

TOURATIER C. (1996), Le système verbal français. Description morphologique et morphématique, Paris : Armand Colin.

VENDLER Z. (1957), “Verbs and Times”, The Philosophical Review 66 (2), 143-160.

VET C. (1980), Temps, aspects et adverbes de temps en français contemporain. Essai de sémantique formelle, Genève : Droz.

VETters C. (1993), "Passé simple et imparfait : un couple mal assorti ", Langue française 100, 14-30.

WAugh L. R. \& MonvilLe-BuRston M. (1986), “Aspect and Discourse Function: the French Simple Past in Newspaper Usage", Language 62, 846-878.

WeINRICH H. (1973), Le Temps, le récit et le commentaire, Paris : Seuil. 